\title{
Analysis and Selection to Diesel Engine Type Spectrum for Fishing Vessel
}

\author{
Yongding WANG ${ }^{1, a}$, Shanshan $\mathrm{WU}^{2, \mathrm{~b}}$ \\ ${ }^{1}$ Department of College of Engineering Science and Technology, Shanghai Ocean University, \\ Shanghai, 201306, China \\ ${ }^{2}$ Department of College of Engineering Science and Technology, Shanghai Ocean University, \\ Shanghai, 201306, China \\ aemail: ydwang@shou.edu.cn, bemail:13818551943@163.com
}

Keywords: Diesel Engine Type Spectrum; Diesel Selection; Power Distribution

\begin{abstract}
This paper analyzes the "fishing vessel with a diesel-type spectral identity management measures" to implement the former fishing diesel chaotic management Phenomenon, through the Ministry of Agriculture announced 570 fishing boats with diesel-type spectral data analysis, with power, speed is statistical indicators, drawn by the domestic fishing engine speed, power distribution, inference may encounter situations when the current domestic diesel engine selection.
\end{abstract}

\section{Introduction}

Over the years due to overfishing of fishery resources, fishers range gradually developed from offshore ocean, fishing master power demand is increasing[1]-[5]. For the limitations of national dual-control policies on the one hand fisherman host power demand, on the other hand diesel engine manufacturers competitive market, there has been fishing the host "big machine small scale", "boat permits inconsistent" and the phenomenon of chaotic management, and long-term exist. The Ministry of Agriculture to strengthen fishing diesel management, science and approved the main parameters of the host power, issued a "fishing boat with diesel-type spectra identification and management approach", the paper published spectral type diesel power, speed to analyze results of the election of the host fishing type range, and future directions[6].

\section{State of Type Spectrum is Not Executed}

\section{Stand-alone power range, an optional power more}

Determined by the characteristics of the diesel engine technology and existing fishing vessel technical regulations and standards, diesel power is a range. When a certain speed, continuous power up to $110 \%$ and $70 \%$ of the maximum continuous power is reasonable[7]. Diesel engine manufacturers to meet market demand, the same type of diesel engine, has a stall speed digital gear calibration block power or a few number of speed gear rated power, and relatively easy to implement.

\section{Power calibration and actual bias, management confusion}

At present, the actual matching host ship around increasing power. Technically take more of the following methods: Turbocharged, increase speed, increase in the cold, and other measures to increase the piston stroke, the host power has been greatly improved, the power value is not the original host plant catalog marked, but shipyards, diesel distributors and production companies and other related parties, by all means a certificate issued by the host power is less than the value of the actual power of the key specifications, materials, nameplates, respectively escape Third crew, ship shafting vibration calculation, two crew members, First manning requirements[8]. These boats are actually chosen gearbox, shafting, propellers and other specifications, dimensions are no match engine power provides. But the surveyor in actual review, no power test equipment, is difficult to directly identify the "big machine small standard" conditions. 


\section{Prone to accidents}

"Great little machine labeled" right the ship's structure, strength, performance, piping equipment, device configuration, gearbox, shaft, propeller selection had a significant impact, and even cause rollover fishing, shaft fatigue fracture and other serious as a result of. Secondly, the power of the chief engineer of the host operating skills requirements, and one of the purposes "big machine small sign" that "small scale" power rating corresponds to the crew, instead of the "big machine" actual power corresponds to a higher level with the appropriate crew level, and therefore may be due to operational skills to keep up causing accidents.

\section{Diesel Type Spectrum Identity Management}

\section{Diesel power point clear fishing}

Ministry of Agriculture and introduce "fishing vessel with a diesel-type spectrum and identity management approach" (the "Regulations") and "fishing vessel with a diesel-type spectrum audit reporting promulgated Rules" (the "Rules"), for fishing vessels with diesel engines (referred to as " Diesel ") the power calibration and identity management were clearly defined[9].

"Management approach" Article IV: "Diesel type spectrum refers to the same base structure (ie bore diesel engine cylinders, stroke, stroke, valve and cylinder arrangement in the form of same) of diesel, due to the speed, and the degree of enhancement Aspiration different scientific analysis and comparison to confirm all product lines. "Thus, the same basic structure of diesel engine can be set to three different calibration speed, each rated speed can only set a rated power. This same type of diesel by reporting, auditing, certification, after the board , power, speed to determine the value, rather than a range, to eliminate the "big machine small scale," the emergence from the source[10]-[13].

\section{Type spectrum coverage}

Diesel type spectrum has been published and is currently in the country with a summary of all fishing vessels $44 \mathrm{~kW}$ diesel main parameters, including 570 diesel model type spectrums. Power from $45 \mathrm{~kW}$ to $5220 \mathrm{~kW}$, speed from $167 \mathrm{r} / \mathrm{min}$ to $3600 \mathrm{r} / \mathrm{min}$, basically covering the range of, boats diesel demand selection. "Management approach" can only have a maximum of nine speed diesel engine, each speed corresponds to a power point, thus covering a wide range of non-contiguous.

\section{Government policy support}

In order to improve fishing diesel type spectrum coverage to meet the needs of fishermen diesel engine selection, the Ministry of Agriculture Bureau of Shipping issued "boats with diesel-type spectrum and identity management approach" (the "Regulations") and "fishing vessel with a diesel-type spectrum released audit reporting Implementing Rules "(the" Rules "), for fishing vessels with diesel power calibration clear, determine diesel power point, rather than a range. And plan in 2015 have been announced for verification type spectrum, so fishing diesel management standardization and institutionalization.

\section{Power Coverage Analysis}

The current domestic production of diesel engine enterprises are mainly distributed in Shandong, Jiangsu and other places, and uneven distribution, there are regional differences. Below is currently the 570 diesel-type spectrum, power distribution. 


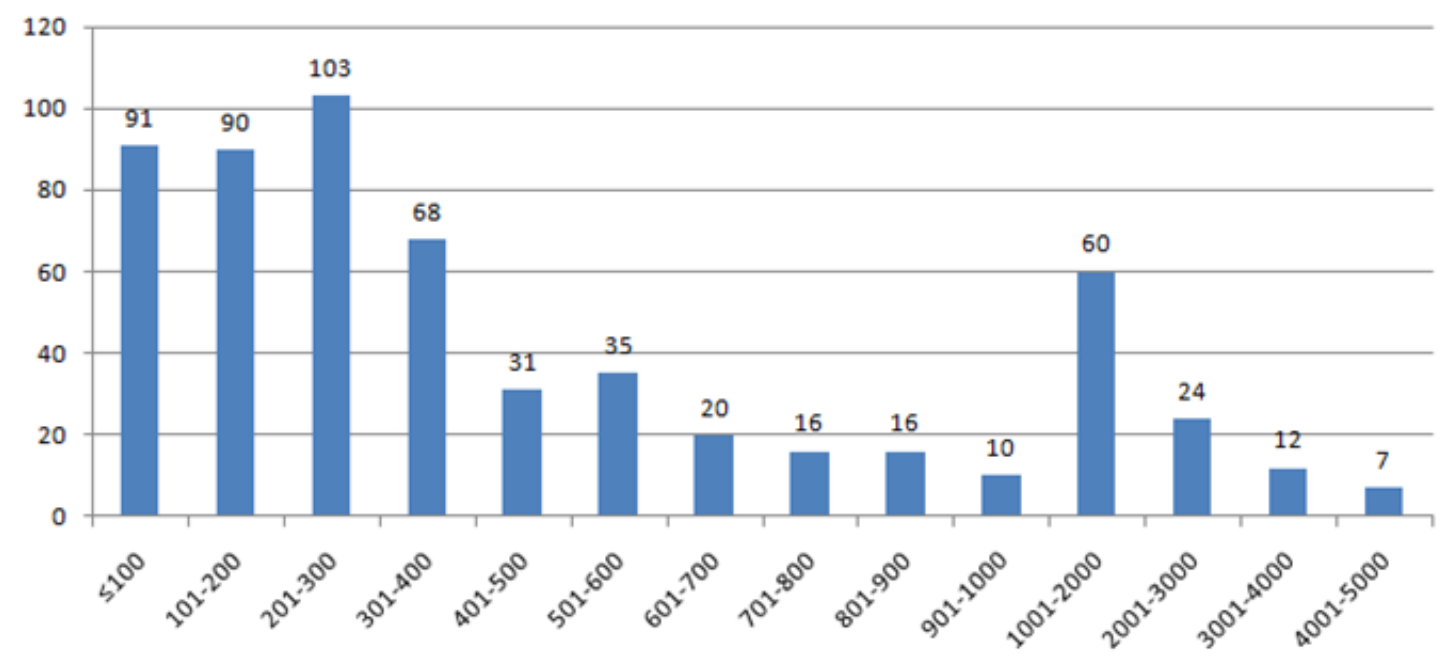

Fig.1. The power distribution

As can be seen from the figure1, the current distribution of engine power between $100-400 \mathrm{~kW}$ lot. To $100 \mathrm{~kW}$ for segmentation, it can be seen, less than $100 \mathrm{~kW}, 100-200 \mathrm{~kW}$, diesel engines are distributed between 90-100, the largest number among 200-300kW; followed between 300-400kW and 1000-2000kW, about 60 ; and between 900-1000 and 4000-5000, the number of small diesel distribution, respectively 10 and 7; a small number of other power range diesel engines and no rules.

570 pairs of diesel-type spectrum speed, power as an index, respectively, speed, power as the horizontal and vertical coordinates, draw a scatter plot.

Speed as the horizontal, the vertical axis of power draw scatter plots is shown below in figure2:

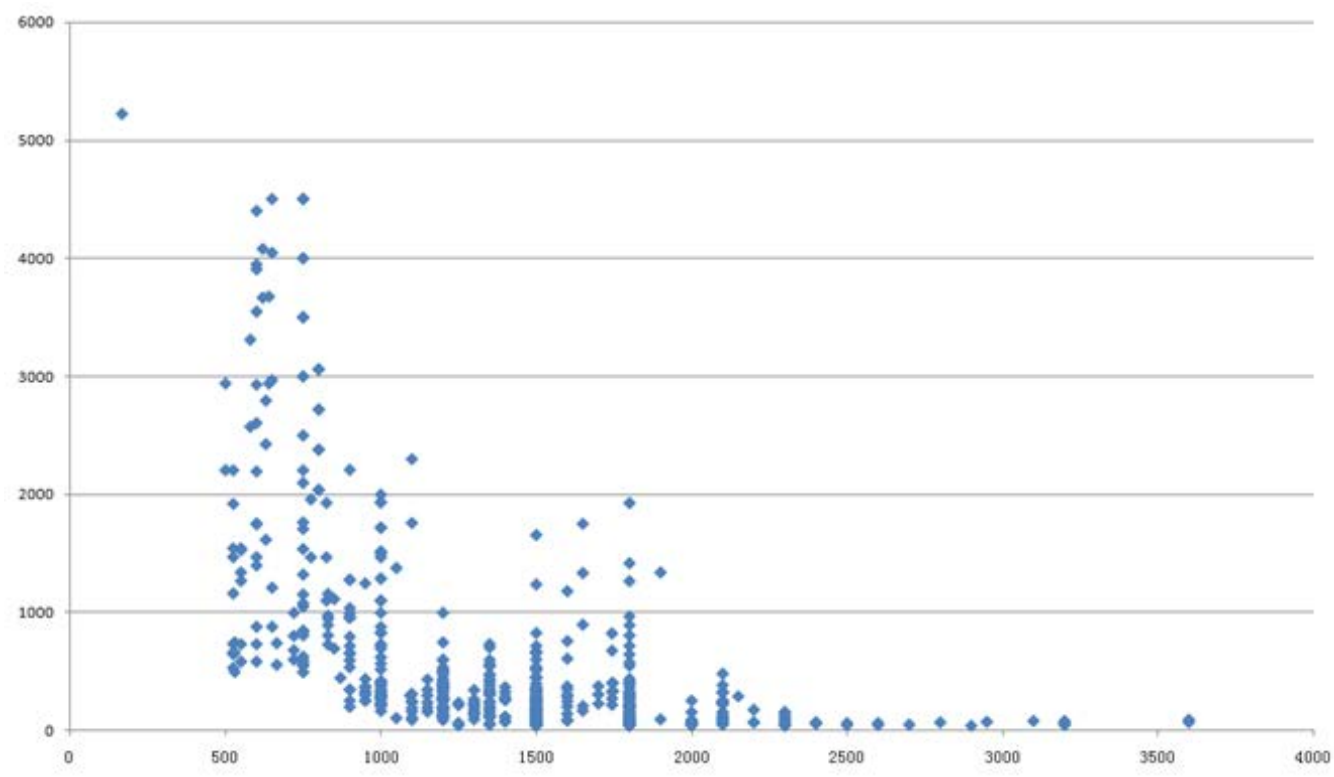

Fig.2. The speed - power diagram

By speed - power diagram, we can see that the current domestic diesel power boats up to 500 -2000r / min speed distribution segment, accounting for $90 \%$ of the total diesel engine, diesel engine choice to meet most of the fishing boats.

The data processing redrawn 500-2000r / min speed diesel engine segment scatter plot: 


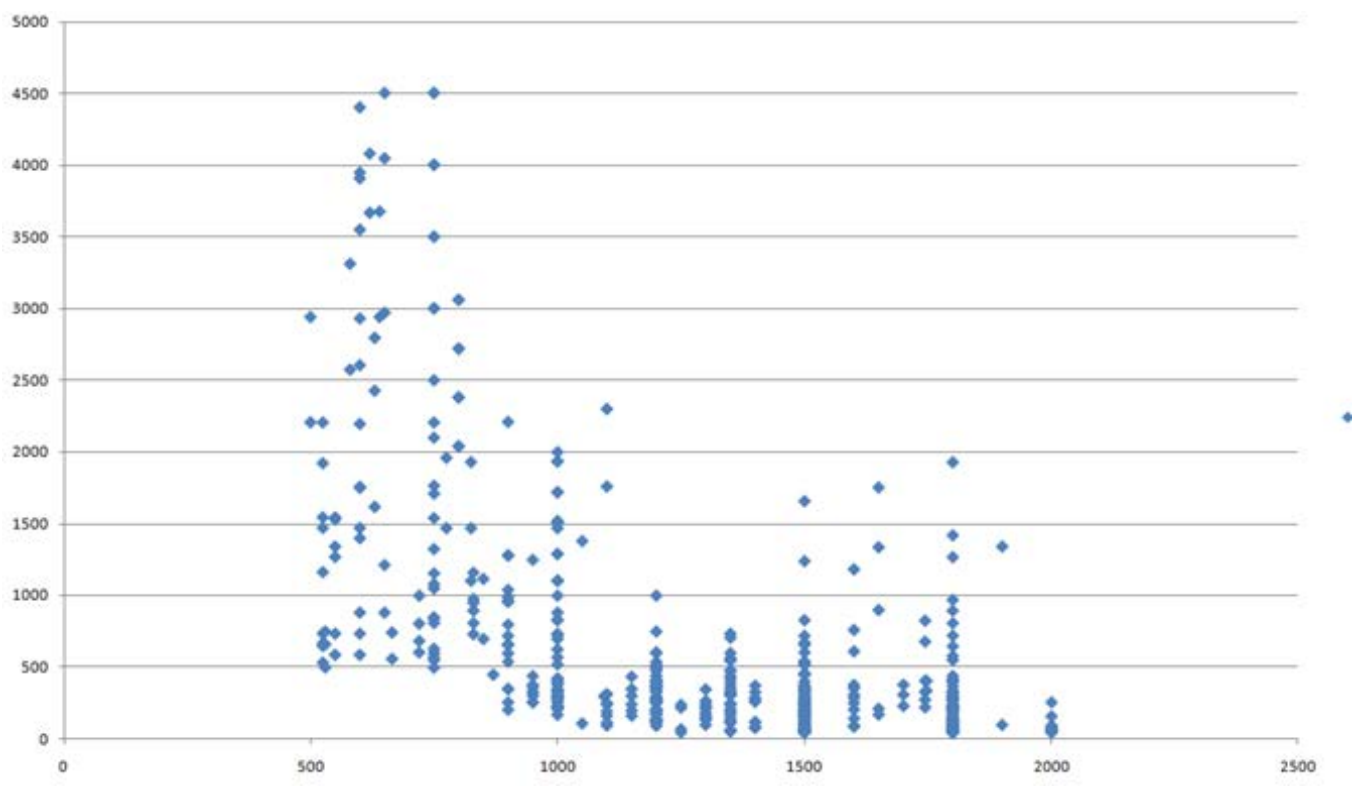

Fig.3. The speed - power diagram

It can be seen in figure3:

(1) When the value of the power of a linear power distribution, such as 1000r / $\mathrm{min}, 1200 \mathrm{r} / \mathrm{min}$, 1300r / min, 1500r / min, 1800r / min when the power density distribution;

(2) Under certain circumstances speed, optional diesel power can range greatly; when such 1000r / min, optional power range $210-2000 \mathrm{~kW}$.

(3) speed is greater than $2000 \mathrm{r} / \mathrm{min}$ diesel selectable power ranges significantly smaller;

(4) speed is less than 500 r / min diesel only one, is the ship Limited production model 6S35ME-B9.3 engine, 6-valve 6-cylinder $350 \times 1550$ big bore stroke diesel engines.

The ability of pick the ball robot has reached theoretical calculation expected. The experiment started with no the institutions, the ball can not very well joint with pick cue, causing pick the ball dynamics change range is very large, and pick the ball height and the average of the theoretical calculation of the distance is smaller than the calculated assumption the height and distance.

After the ball add tape loading agencies, institutions force the ball the reverse spin, the ball close to pick the cue, pick the ball transfer fully energy to the ball, pick the ball effect is obvious stable. But it is found that the actual pick the ball after add tape loading agencies less than the theory calculated average distance.

\section{Typical enterprise}

There are several domestic production of diesel typical enterprise, such as Shandong Zibo Diesel Corporation, Weichai Group Holdings Limited under Weichai Heavy Machinery, Weichai Power Co., Ltd., Jiangsu, China Shipbuilding Limited, Guangxi Yuchai Machinery shares Limited.

The following figure, a company 74 type spectrum for data and draw a scatter plot. 


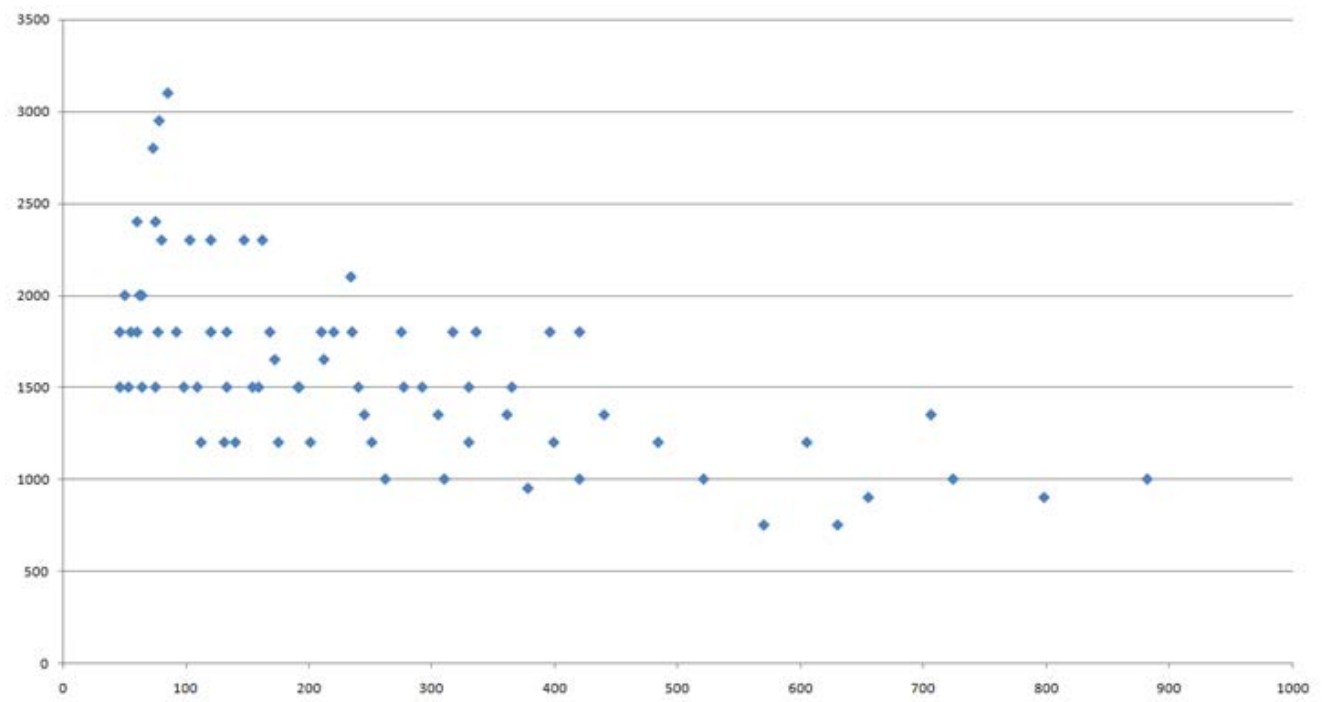

Fig.4. The speed - power diagram

It can be seen in the figure4,

(1) The company is mainly distributed within the power $900 \mathrm{~kW}$, more densely distributed within $500 \mathrm{~kW}$

(2) speed is mainly distributed in the outer 1000-2500r / min, the range of the number of very small;

(3) at a rotational speed point, the power distribution is linear, such as $1200 \mathrm{r} / \mathrm{min}, 1500 \mathrm{r} / \mathrm{min}$, $1800 \mathrm{r} / \mathrm{min}$.

\section{Conclusion}

1) At present, diesel boats throw uneven power distribution, dispersion is strong, at different speeds, the power to select the range of differences in circumstances likely to occur when a large selection.

2) Fishing host selection, less than $2000 \mathrm{~kW}$ type spectrum can basically cover all the power is significantly reduced the number higher than $2000 \mathrm{~kW}$ diesel engines, and discontinuous, even if there is $5 \%$ less power float will be selected when the presence of the machine selection .

3) speed when 500-2000r / min, engine power distribution is relatively dense, easy to choose, and the basic structure of the same engine, different production, different power calibration can compare options.

4) The speed is different selectable power range are very different, there are two significant features, i.e. a certain speed point power density distribution, but a small range of options; the other is at a rotational speed of the power distribution point sparse, but selected range, it is not likely to cause the election less than a suitable power point situation.

5) It can be seen from the speed, power figure, diesel power point sparse areas, there is still room for the development of new models, the government should give policy support, and at any time according to the actual situation of the current management regime to improve and ensure the management towards diesel more scientific and rational direction.

\section{Acknowledgements}

This work was financially supported by Special Fund for Science and Technology Commission of Shanghai Municipality innovation action plan (13dz1203701) and Supported by Special Fund for Key Project of Shanghai Municipality Agricultural Science and Technology Research (2014) No.6-3. 


\section{References}

[1] Zou this strong status quo and development trend of marine diesel engine [J], 2006 (6): 10-12

[2] Chen Yanming development, Yu Lin shows, high-speed marine diesel engine, Chinese waterway [J], 2003 (12): 44-45

[3] Huang Qiang high waves "big machine small scale" hidden more [J] Chinese ship inspection, 2014,4: 102-103.

[4] Liu Shunbin Improvement of Fisheries "dual control" system [J] China Fishery, 2009,7: 24-25.

Study [5] European Hwan Kang Yu Cong up fishing vessel "dual control" system effectiveness [J] Zhejiang Ocean University, 2011,3 (5):... 432-435.

[6] Qiuhua Zhang Cheng Jia Hua Xu Han-like, such as the East China Sea and the sustainable use of resources and their performance [M] Shanghai: Fudan University Press. 2007: 587.

[7] Zheng Yuzhu, fishing master real power and nameplate power causes and hazards inconsistent [J] Fishery Machinery and Instrument, 2011,30 (5): 36-37.

[8] Li Shuang, the Ministry of Agriculture issued fishing diesel type spectrum and identity management approach with [J] China Fishery, 2014,3: 11.

[9] The new swim away, fishing host selection overview, Fisheries Modernization [J], 1997 (2), 28-31

[10] Liu Zuocheng, diesel boats on the selection, Fisheries Modernization [J], 1985 (6) 42

[11] Ma Shuai Peng Zhuorong host selection of new trends, diesel engine [J], 2013 (1), 13-16

[12] Development and Prospects Mei Chun, the selection of the host ship, diesel engine [J], 2012 (1), 7-12

[13] Wengwen Yao discussed issues concerning fishing host selection, Fujian Fisheries [J] 1988 (4), 30-33 